\title{
Problems of Fundamentalization of Higher Social Education
}

\author{
Nailya Shaukatovna Valeyeva \\ Department of Social work, Pedagogics and Psychology \\ Kazan National Research Technological University \\ Kazan, Russia \\ vnaila53@mail.ru
}

\begin{abstract}
This study focuses on the fundamentalization of higher education in general and social education in particular. Over the last years it has become clear that the new time and growing complexity of the system of economic, social and cultural relations require the training of a new type specialists with a broad, universal basic background and fundamental knowledge. The fundamentalization of education includes focusing of education on the study of the basic laws of nature and society, as well as the nature and purpose of mankind. Such approach shall make it possible for social workers to find and make responsible decisions in uncertain, critical and stressful situations, when faced with new complicated natural and social phenomena.
\end{abstract}

Keywords - fundamentalization of education, fundamental and applied knowledge, social education, anthropologization.

\section{INTRODUCTION}

As the rate of technological, scientific and technical progress accelerates, it brings with it that a lot of knowledge rapidly becomes obsolete, and it is unacceptable to leave it out of consideration when it comes to the education system. Which is why the main attention should be paid to the development of creative qualities of a person, his/her abilities to make decisions independently in uncertain situations, as well as to the development of the learning skills and the ability to gain new knowledge.

The fundamentalization of modern education, which allows one to overcome the disconnection of science and liberal education, the narrowness of specializations, excessively pragmatic orientation of many academic disciplines, can solve this problem. These are the characteristics of the existing system of social education that make it difficult for future social workers to form a full picture of many natural and social phenomena and the patterns of their further development, which is rather important for their successful professional occupation.

The works of many scientists focus on the problem of education fundamentalization. The essence of the problem is described by such scientists as B. M. Kedrov [1], V. G. Kinelev [2], A. I. Subbeto [3], A. D. Ursul [4], etc. The fundamentalization of higher education was analyzed in the works of A. A. Verbitsky [5], E. N. Gevorkyan, D. Trubetskov, D. Usanov [6], A. D. Sukhanov [7], V. M. Filippov, V. P. Tikhomirov [8] and others.

\author{
Galiya Bulatovna Khasanova \\ Department of Social work, Pedagogics and Psychology \\ Kazan National Research Technological University \\ Kazan, Russia \\ ufkbz58@mail.ru
}

The concepts of fundamentalization of professional education are described in the works of O. N. Golubeva, V. Kagermanyan, A. Savelyev, A. Sukhanov [9], V. V. Kondratyev [10], A. M. Novikov [11], S. Ya. Kazantsev [12], G. B. Khasanova [13].

The study is based on anthropological, activity-based, systematic and holistic approaches which allow one to solve the problems of education fundamentalization. We have analyzed the distinctive characteristics of the knowledge fundamentality in dialectical unity with their applied characteristics.

\section{GENERAL APPROACHES TO THE FUNDAMENTALIZATION OF EDUCATION}

The fundamentalization of education includes focusing of education on the study of the basic laws of nature and society, as well as the nature and purpose of mankind. Such approach makes it possible for people to find and make their own responsible decisions in uncertain, critical and stressful situations, when faced with new complicated natural and social phenomena. In these cases, scientific knowledge and high moral principles are of great support.

The fundamentality is based on such content of education, the priority of which is methodologically important, longterm, invariant knowledge which contributes to the holistic perception of the scientific picture of the world, intellectual development of an individual and his/her adaptation in rapidly changing social, economic and technological conditions [7]. Therefore, we need new objectives and principles of selection and systematization of knowledge, which will make it possible to develop fundamental training courses in each of the traditional science, liberal and technical disciplines and coordinate them with each other in order to achieve a new quality of education of an individual.

Education can be considered fundamental if it is a "process of nonlinear interaction of a person with intellectual environment, wherein the person perceives it in order to enrich his/her inner world and as a result matures to multiply the potential of the environment itself" [14]. The purpose of such education is to provide optimal conditions for raising flexible and comprehensive scientific thinking, different ways of perceiving the reality, and to create an internal need for selfdevelopment throughout a person's life. 
P. I. Pidkasisty, L. M. Fridman, M. G. Garunov [18] point out that fundamental knowledge is scientific, highly theoretical, abstract knowledge which reveals the primal laws of natural and social reality, becoming significant on a practical level by itself rather than through any special, applied researches and developments; these are structural units of scientific knowledge that have such level of generalization of the reality phenomena and their "relations" in them that all other versions of these knowledge units are special cases under certain limitations of the parameters of the original structural units.

Under this approach, in our opinion, instead of a large number of separate phenomena, invariant structural units of scientific knowledge and fundamental knowledge, which explains the meaning of facts and phenomena observed in this discipline, can be distinguished in the content of education. Students who have gained such knowledge can further handle all other cases without special training.

Thus, the main purpose of the training becomes not an intensive study of some fundamental disciplines, but fundamentalization of knowledge of the natural and social laws that do not change during changing of social and economic conditions, development of technics and technologies and specific character of their practical application - applied knowledge. Applied knowledge is knowledge that makes it possible to solve specific professional tasks. However, applied disciplines also contain knowledge that can be called fundamental, as it represents a mix of scientific generalizations made in different applied sciences.

Thus, we can name the following characteristics of fundamental knowledge in the content of education [13]:

- focus on ensuring the integrity of perception of the scientific worldview;

- focus on ensuring the consistency of knowledge;

- focus on ensuring the continuity;

- focus on ensuring the flexibility of knowledge;

- formation of the ability to synthesize with knowledge from other areas, to form interdisciplinary knowledge.

The fundamental knowledge is a frame that holds the rest of knowledge and experiences of the rapid life. It is a basis for the formation of a general and professional culture, fast adaptation to new professions, specialties and specializations, since firstly, it allows to form a broad, holistic, encyclopedic view of the modern world and the place of a person in this world; and, secondly, it allows to overcome the discipline disconnection and isolation [19].

Therefore, a modern specialist has to have general methodological, system-wide ideas and understand relations of fundamental, general professional and special knowledge [20]. This knowledge cannot be gained automatically, it is developed by the person as a result of his/her internal creative activity [19].

The fundamentalization of education includes application of the following principles of selection of the optimal scope of 
3) to develop and implement a model of knowledge needed to be digested by students with regard to their sufficient minimum scope.

First, we need a reasonable approach to the formation of the scope and content of professional education which complies with both the purposes of the development of the person, his/her further professional self-fulfillment, and the interests and needs of social practice.

Second, a sufficient minimum scope should be considered with regard to specific levels, kinds and forms of professional education, where this minimum scope has a certain specificity.

Third, a sufficient minimum scope of knowledge as a category should be implemented through an educational standard - and, above all, in terms of the necessary minimum content of the main educational programs.

According to L. S. Yolgina, the peculiarities of fundamental higher education are:

- continuity of education in time and its globality in space;

- teaching a person creative development throughout his/her life with prevailing of self-education;

- individualization and increasing variety of educational standards;

- $\quad$ transition from formal and disciplinary to problematic and active type of teaching [21].

Therefore, a new educational paradigm for the forthcoming Information Society can be formulated as a logically related triad: "From the holistic view of the World towards the holistic Knowledge and, thus, towards the holistic Personality" [19].

\section{THE CONCEPT OF FUNDAMENTALIZATION OF PROFESSIONAL EDUCATION OF SOCIAL WORKERS}

The fundamentalization of professional education makes it possible to employ achievements of fundamental sciences in professional training of students, to create one methodological basis for studying numerous kinds of narrowly-specialized knowledge, to build a so-called belief system in which any knowledge has its place. All of this, in our opinion, will allow students to deepen their understanding of their future profession and facilitate to have a smooth start in it, to develop a commitment to the results of their activities, and to ensure professional growth.

A. N. Khodusov suggests building a system of fundamentalization of professional education in a modern university by the following stages [22]:

1) to get the subjects of professional education of the university motivated for implementation of the education fundamentalization strategy on the basis of its internalization as a personal value;

2) to adapt the modern concept and holistic theory of fundamentalization of professional education to the educational space, environment and educational system of the university; fundamentalization of professional education in the university which should be created on the basis of a problem-modular technology with distinguishing fundamentalization modules in the discipline units.

According to Yu. Shikhov and V. Cherepanov, the "keystones" of fundamentalization of higher technical education are:

- information unit that develops the need for education (training in human sciences, worldview formation, training in physics and mathematics, informational training, verbal and linguistic training, national and cultural training, creative training, reflexive and methodological training, training in civil law, ethics and educational training);

- $\quad$ systematology and classification training focused on the formation of meta-knowledge which allows to increase the productivity of acquisition of knowledge by using the technology of information reduction (philosophy, logic, mathematics, cybernetics, qualitology);

- general professional training (technological, economics, environmental, creative, qualitology and qualimetry, organizational and administrative, as well as competence training) [23].

The researchers suggest to implement the proposed paradigm of fundamentalization of higher technical education in the following directions:

- $\quad$ restructuring the content of education by conducting a transition to four macroblocks (natural science, technical science, social science and study of human

- introduction of classiology and qualitology;

- informatization of functioning mechanisms of different kinds of knowledge;

- development of the theory of technologization of any kinds of activity;

- development of the study on cyclical development of any systems, including technical ones.

According to A. V. Balakhonov [24], the essence of the phenomenon of fundamental nature of higher medical education based on the system of scientific knowledge lies in the methodological orientation of the professional education, which is achieved due to the including of the theoretical knowledge, general concepts, general scientific ideas, laws and principles to the content of education, as well as using research methods of training and creative activity, students' personal development. The author sees fundamental medical education as an integration of natural and medical sciences in the training process of health care workers.

Therefore, fundamentalization of professional education is defined by special characteristics of professional activity of future specialists. nature); 
In this study, we have attempted to adapt the general concept of fundamentalization of higher education to the field of professional education of social workers, which is a component of the entire higher education system, but is characterized by a certain specificity.

The specificity of professional social education in general and professional education of social workers in particular, lies in the complexity and multiplicity of the object of their professional activity - a person. For a social worker, a person is interesting as a whole, in the unity of his/her biological, psychological, social and spiritual qualities. This important theoretical thesis is one of the methodological principles of social work which implies relying on an integrative, holistic concept of a person, focusing on the establishment of interdisciplinary connections between all anthropological disciplines.

The main difficulty in this case is that the most fundamental characteristic of the modern human study is the division of knowledge into two disciplines - natural science and human science with no direct connection between each other. In order to understand the integrity of a person, we need to realize the fact that human and natural science knowledge gives different pictures of the same reality. The subject of the human science knowledge is the objectified part of this reality, which can be described by finite means with the use of formal logic. Whereas the subject of the natural science knowledge is the process of formation of the objectified reality, i. e. the subjective activity. Ultimately, the subject of the knowledge is the same, but belongs to different areas. The pictures of the reality complement each other, but are not mutually exclusive. It is wrong to speak about any quality of a person separately - each of them is a part of a complete system.

The fundamentalization of education as a process includes fundamentalization of the content of education (of the knowledge) as a subprocess. Due to the fact that the fundamentalization of education can be seen as a process of fundamental knowledge transmission, there are features of both the main process and those of subprocess in the below conceptual characteristics of the concept of social education fundamentalization defined by us based on the general concept by A. I. Subetto [3].

The concept of fundamentalization of social workers' professional education is formulated by us as the following key theses [13].

1. The fundamentalization of social workers' professional education is a continuous process both in terms of the institutional scale and at the personal level.

2. The fundamental nature of knowledge of a social worker shall not be narrowed down to the fundamental nature of natural science knowledge since in all discipline courses that form the content of training there is a "layer" of fundamental knowledge.

Prior to the introduction of the third generation standards, the fundamental nature of knowledge of humanities was narrowed down to the study of the Modern Scientific Worldview course which combined the study of physics, chemistry, biology and ecology, and to the increase of the classroom hours for the study of mathematics and computer science. Today, universities determine the list of disciplines of the education plan of their professional training depending on their own ideas about what students should be taught to.

3. The fundamental education of a social worker should comprise of both theoretical and fundamental and professional and fundamental training. The theoretical and fundamental training includes: philosophy, mathematics, Modern Scientific Worldview, computer science, anthropology; the professional and fundamental training consists of fundamental, general professional disciplines included in human science and social and technological courses.

4. The fundamentalization of education is the basis for the formation of general and professional culture, coping with adaptation barriers on the way toward the change of labor functions.

The fundamental nature of knowledge of social workers implies:

- interdisciplinarity achieved through the synthesis of knowledge with the help of specially developed integrative training courses;

- flexibility, i. e., focusing on the perception of the world and a person as a whole achieved through the synthesis of knowledge due to the formation of periodically changing personal world views as the final points of educational courses [25];

- $\quad$ problematical nature characterized by the synthesis of knowledge evoked by the need of solving professional issues.

Let us analyze conceptual characteristics of the proposed concept of professional education of social workers.

The continuity of the fundamentalization process must be considered at the institutional and personal level. At the institutional level, the continuity means the mandatory presence of a fundamental component in all courses of programs of higher social education including general professional and major disciplines [26]. As for the personal level, "understanding of fundamental knowledge" takes different forms throughout the entire process of the study at a university. The cyclicity of fundamentalization of knowledge is formed "in the categories of educational courses" [3], either of which begins with the previous personal world view and ends with a new world view.

In our opinion, the main direction of fundamentalization of social workers' professional education is anthropologization, which implies reproduction of a holistic image of a person in the content of social workers' education based on the synthesis of fundamental ideas of biological, psychological, pedagogical and social education in the integrated structure of anthropological training [27].

The principle of fundamentalization in anthropological training makes it possible for students to acquire the invariant part of knowledge about a person as a whole, which forms the basis for professional readiness of a worker and creative personal development of a social worker in a changing world. 
This principle means a targeted comprehensive organization of the content of professional social education based on interrelations of methodological, ontological, naturalscientific, social and psychological ideas which enhance the status of educational disciplines to the level of fundamental ones. The principle of fundamentalization allows one to incorporate human science disciplines into one course combined by one target function and interdisciplinary connections, which ensures integrity of professional training of social workers. In this context, we have distinguished three interrelated modules in the structure of anthropological training of social workers: medical-biological, psychologicalpedagogical and sociological modules, either of which comprises of a set of academic disciplines containing fundamental knowledge of different qualities of a person: natural, psychological and social.

The implementation of the proposed concept of fundamentalization of professional social education will allow one to overcome narrowly-specialized professionalism, fragmentary consciousness and fragmentary intelligence of the workers, and to form by students such basic fundamental knowledge and skills that they will be able to transfer to a new field of activities in the future and, therefore, to adjust to different areas of social work practice.

\section{CONCLUSION}

In connection with the general tendency of the development of civilization and drastic change of the role of education in the modern world, the ideas about its fundamental nature have undergone significant changes. The objective reasons for concept development of fundamentalization of social workers' professional education are the changes in the social and economic life of society and the reforms made in the education system.

Developed based on the general concept of higher education fundamentalization, the fundamentalization concept of social workers' professional education is based on the idea that it is a continuous process, on the idea of the irreducibility of the fundamental nature of a social worker's knowledge to the fundamental nature of scientific knowledge, on the need to form a general and professional culture of the specialist by including human science disciplines to the training process.

The concept of fundamentalization of professional training of social workers developed by us can be used as a basis for development of other concepts of fundamentalization of professional education of various profile specialists.

\section{References}

[1] B.M. Kedrov, Classification of Sciences. K. Marx's Forecast on the Science of the Future, Moscow: Mysl', 1985, pp. 543-559.

[2] V.G. Kinelev, "Education and civilization" Higher education in Russia, vol. 3, pp. 4-12, 1996.

[3] A.I. Subetto, Problems of fundamentalization and sources of the formation of the content of higher education: the adges of public policy, Kostroma: Kostroma Pedagogical University, 1995, pp. 23-25.

[4] A.D. Ursul, "Culture as an Information Phenomenon" Philosophical thought, vol. 8, pp. 295-355, 2013.
[5] A.A. Verbickij, Theory and technology of contextual education Moscow: MPSU, 2017.

[6] E. Gevorkyan, D. Trubeckov, D. Usanov, "Fundamentalization of university education" Higher education in Russia, vol. 2, pp. 61-62, 1998.

[7] A.D. Suhanov, "The concept of fundamentalization of higher education and its reflection in the State educational" Higher education in Russia, vol. 3, pp. 17-24, 1996.

[8] Zh.N. Zajceva, Yu.B. Rubin, L.G. Titarev, V.M. Filippov, V.P.Tihomirov, Open Education - XXI Century Strategy for Russia, Moscow: MESI, 2000.

[9] O. Golubeva, V. Kager'man'yan, A. Savel'ev, A. Suhanov, "How to reform general science education" Higher education in Russia, vol. 2, pp. 48-54, 1997.

[10] V.V. Kondrat'ev, "Fundamentalization of specialist professional education at the technological university" Kazan: Kazan Technological University, 2000.

[11] A.M. Novikov, Russian education in a new era. Paradoxes of heritage. Development vectors Moscow: Egves, 2000.

[12] S.YA. Kazancev, Didactic fundamentals of the fundamentalization of education in higher education, Kazan: Kazan Technological University, 2000.

[13] G.B. Khasanova, The fundamentalization of social education, Kazan: Kazan Technological University, 2003, pp. 158-159.

[14] F.I. Peregudov, "Systemic Activities and Education, Higher Education Quality" Computer Science and Education, vol. 1, pp. 18-19, 1990.

[15] B.C. Kagerman'yan, M.G. Garunov, Influence of the development of science, technology, economy and culture on the content of higher education, Moscow: NIIVO, 1996, pp. 34-35.

[16] A.I. Markushevich, Improving education in the scientific and technological revolution Moscow: Pedagogy, 1973, p. 220.

[17] O.V. Dolzhenko, Essays on Philosophy of Education Moscow: PROMO-Media, 1995, p. 127.

[18] P.I. Pidkasistyj, L.M. Fridman, M.G. Garunov, Psychological and didactic reference book of a teacher of higher education Moscow: Pedagogicheskoe obshchestvo Rossii, 1999, p. 203.

[19] V.G. Kinelev, "Fundamentalization of university education" Higher education in Russia, vol. 4, pp. 6-13, 1994.

[20] A.A. Kirsanov, Methodological problems of creating a prognostic model of a specialist Kazan: Kazan Technological University, 2000, p. 9.

[21] L.S. Yolgina, "The value of fundamentalization of education and its role in the preparation of university students in the modernization of the educational system" Bulletin of the Buryat State University, vol. 3, pp. 88-92, 2015.

[22] A.N. Hodusov, "Fundamentalization of professional education", Scientists notes. Electronic scientific journal of Kursk State University, vol. 3, pp. 140-147, 2017.

[23] Yu. Shihov, V. Cherepanov, "To the problem of fundamentalization of higher technical education" Higher education in Russia, vol. 6, pp. 145147, 2007.

[24] A.V. Balahonov, "The fundamentalization of higher medical education based on systemic science" Bulletin of St. Petersburg University, vol. 1, pp. 136-141, 2006.

[25] Yu.N. Semin, Theory and technology of integration of the content of vocational training in the technical university, Izhevsk, 2001, p. 158.

[26] G.B. Khasanova, N.Sh. Valeyeva, R.V. Kupriyanov, M.I. Nadeyeva, I.R. Zaripova, R.N. Zaripov, E.V. Gafiyatova, "Social discourse models for pre-service professionals," Modern Journal of Language Teaching Methods, vol. 8(10), p. 52-62, November 2018.

[27] G.B. Khasanova, N.Sh. Valeyeva, R.V. Kupriyanov, I.R. Zaripova, N.N. Melikhova, R.N. Zaripov, M.I. Andreeva, "Anthropological training as a means of formation of professional competence of a social worker," Modern Journal of Language Teaching Methods, vol. 8(10), p. 129-135, October 2018. 